This item was submitted to Loughborough's Research Repository by the author.

Items in Figshare are protected by copyright, with all rights reserved, unless otherwise indicated.

\title{
A quantitative approach for understanding small-scale human mesenchymal stem cell culture implications for large-scale bioprocess development
}

PLEASE CITE THE PUBLISHED VERSION

http://dx.doi.org/10.1002/biot.201200197

\section{PUBLISHER}

(c) WILEY-VCH Verlag GmbH \& Co.

\section{VERSION}

AM (Accepted Manuscript)

\section{LICENCE}

CC BY-NC-ND 4.0

\section{REPOSITORY RECORD}

Rafiq, Qasim A., Karen Coopman, Alvin W. Nienow, and Christopher J. Hewitt. 2015. "A Quantitative Approach for Understanding Small-scale Human Mesenchymal Stem Cell Culture Implications for Large-scale Bioprocess Development". figshare. https://hdl.handle.net/2134/17982. 
A quantitative approach forunderstanding small-scalehuman mesenchymal stem cell culture -implications for large-scale bioprocess development

\author{
Qasim A. Rafiq ${ }^{1}$, Karen Coopman ${ }^{1}$, Alvin W. Nienow ${ }^{1,2}$, and Christopher J. Hewitt ${ }^{{ }^{*}}$ \\ ${ }^{1}$ Centre for Biological Engineering, Department of Chemical Engineering, Loughborough University, \\ Leicestershire, LE11 3TU, United Kingdom. \\ ${ }^{2}$ School of Chemical Engineering, University of Birmingham, Edgbaston, Birmingham, B15 2TT, \\ United Kingdom.
}

*Author for correspondence. (Telephone: +44-1509 222506; Fax: +44-1509 222506; E-mail: c.j.hewitt@lboro.ac.uk)

Keywords: bioprocessing, human mesenchymal stem cells, regenerative medicine, hypoxia, normoxia

Abbreviations: hMSC, human mesenchymal stem cell; $\mathbf{d O}_{2}$, dissolved oxygen; ATP, adenosine 5'triphosphate; NADPH, nicotinamide adenine dinucleotide phosphate; DMEM, Dulbecco's Modified Eagle Medium (DMEM); FBS, foetal bovine serum 


\begin{abstract}
Human mesenchymal stem cell (hMSC) therapies have the potential to revolutionise the health- care industry and replicate the success of the therapeutic protein industry; however, for this to be achieved there is a need to apply key bioprocessing engineering principles and adopt a quantitative approach for large-scale reproducible hMSC bioprocess development. Here we provide a quantitative analysis of the changes in concentration of glucose, lactate and ammonium with time during hMSC monolayer culture over 4 passages, under $100 \%$ and $20 \%$ dissolved oxgen $\left(\mathrm{dO}_{2}\right)$, where either a $100 \%$, $50 \%$ or $0 \%$ growth medium exchange was performed after $72 \mathrm{~h}$ in culture. Yield coefficients, specific growth rates $\left(\mathrm{h}^{-1}\right)$ and doubling times (h) were calculated for all cases. The $100 \% \mathrm{dO}_{2}$ flasks outperformed the $20 \% \mathrm{dO}_{2}$ flasks with respect to cumulative cell number, with the latter consuming more glucose and producing more lactate and ammonium. Further- more, the $100 \%$ and $50 \%$ medium exchange conditions resulted in similar cumulative cell num- bers, whilst the $0 \%$ conditions were significantly lower. Cell immunophenotype and multipotency were not affected by the experimental culture conditions. This study demonstrates the importance of determining optimal culture conditions for hMSC expansion and highlights a potential cost savings from only making a 50\% medium exchange, which may prove significant for large-scale bioprocessing.
\end{abstract}




\section{Introduction}

The next healthcare revolution will apply regenerative medicines; creating cell based biological therapies or biological substitutes for the replacement or restoration of tissue function lost through failure or disease [1]. Human mesenchymal stem cells (hMSCs) have been considered as a potential cell source for regenerative medicine applications and offer a number of advantages when compared to other cell types including their relative ease of isolation, multipotency, high in vitro expansion potential, established therapeutic efficacy, acceptability ethically and low immunogenicity [2,3]. However, whilst science has revealed the potential of such therapies and early adult stem cell-based products have shown their power [4], there is now a need for the long term supply of adult stem cells, including hMSCs, in sufficient numbers to create reproducible and cost effective therapeutic products. Whilst many of the challenges that lie ahead are biological, others lie under the largely untapped remit of the engineer.

As with the therapeutic protein industry, measure- ment and control of culture parameters is crucial, with even small changes in culture conditions having a poten- tially significant effect. Currently, the expansion of hMSCs typically involves the in vitro culture of cells as a monolayer in T-flasks under static conditions, with measurements usually limited to cell viability, confluency and those related to post-culture functionality. However, it is our contention that in order to inform the basis of the development of the larger scale production of hMSCs, the factors controlling the process need to be fully under- stood by the engineer. A key analytical tool used in engineering is the principle of mass balance [5]. However, it has not been possible to develop an accurate mass balance calculation for hMSC T-flask culture as nutrient usage, metabolite production and headspace gas com- position are not routinely measured. It is, however, widely accepted that, for mammalian cells used in the pro- duction of heterologous recombinant proteins (e.g. CHO, HEK, etc.), glucose and glutamine are vital nutrient sources for the generation of adenosine 5'-triphosphate (ATP) and the reduced form of nicotinamide adenine din- ucleotide phosphate (NADPH), with glucose being utilised either by oxidative phosphorylation or via the process of anaerobic glycolysis [6]. A priori, adequate lev- els of glucose and glutamine are probably critical for the growth of hMSCs in vitro to avoid nutrient supply being rate-limiting. Likewise, it has been established that the cellular metabolism of glucose and glutamine results in the production of toxic metabolites, such as ammonium and lactate, which are secreted into the medium and inhibit cell growth. Thus, the combination of an insufficient nutrient supply as well as the accumulation of waste products in the medium can have a significant effect on cell growth rate, viability [6] and in the case of cells used for therapeutic purposes, their future functionality.

In conventional mammalian cell culture, the level of dissolved oxygen $\left(\mathrm{dO}_{2}\right)$ in the growth medium is also important and as such is always measured and often carefully controlled. 
Unfortunately, there is a disparity between the nomenclature used to describe the oxygen concentration present in the cells' growth medium in the bioprocess engineering and life sciences fields, which may lead to confusion when trying to understand the significance of results. With so much experience already available concerning the growth of animal cells on the large scale, it would seem advantageous to bring the two into line. The levels of oxygen usually described by the term "normoxia" (20-21\% v/v oxygen in the headspace) is equivalent to $100 \% \mathrm{dO}_{2}$ in the culture medium when saturated with respect to air; whilst the term "hypoxia" (2-5\% v/v oxygen) is equivalent to $10-25 \% \mathrm{dO}_{2}$. The problem is further exacerbated because when compared to the $\mathrm{dO}_{2}$ that hMSCs experience in the body (discussed later), $100 \%$ $\mathrm{dO}_{2}$ ("normoxia”) would generally be considered "hyperoxic" physiologically, whilst a reduced $\mathrm{dO}_{2}$ is more likely to be "normoxic" physiologically. Therefore by considering the oxygen concentration in terms of the nominal $\% \mathrm{dO}_{2}$ with respect to saturation in the liquid medium, which is the standard nomenclature in biochemical engi neering, some of these ambiguities can be reduced.

A review of free-suspension animal cell culture in large-scale bioreactors indicated that they were typically controlled at $\sim 50 \% \mathrm{dO}_{2}$, though the actual value varied from process to process. On the other hand, satisfactory performance with some cell lines had been observed at the bench-scale with anywhere from 5\% to 100\% saturation [7]. However, the literature did not noticeably refer back to the cells' origin when selecting the value used. The $\mathrm{dO}_{2}$ concentration in the bone microenvironment within the body has been mathematically modelled and shown to be in equilibrium with a range of between $1 \%$ and $6 \%$ saturation [8,9]. Recently, it has been shown that the oxygen concentration in the incubator in which the Tflasks are contained has a significant effect on the expansion of hMSCs. The most commonly held belief is that the oxygen concentration experienced by the cells in the growth medium should mimic the in vivo physiological conditions from which the hMSCs have been derived, in this case, bone marrow. However, there are conflicting results. Work has shown [10-12] that under "normoxic" conditions (i.e. $20 \% \mathrm{O}_{2} / 75 \% \mathrm{~N}_{2}, 5 \% \mathrm{CO}_{2} \mathrm{v} / \mathrm{v}$ in the incubator, nominally $\equiv 100 \% \mathrm{dO}_{2}$ ), the expansion of hMSCs is inferior to that obtained under so-called "hypoxic" conditions ( 2-5\% $\mathrm{O}_{2} \mathrm{v} / \mathrm{v}$ in the incubator, nominally $\left.\equiv 10-25 \% \mathrm{dO}_{2}\right)$. Other studies, however, have demonstrated that, based on the concentration in the incubator, $10-25 \% \mathrm{dO}_{2}$ ("hypoxia") can have an impact on either cell quality by attenuating cell differentiation [13] or cell quantity by reducing cell proliferation [14] in comparison to $100 \% \mathrm{dO}_{2}$ ("normoxia"). However it should be pointed out in passing that the hMSCs used in the study by Holzwarth et al. [14] were obtained from bone marrow aspirates of children with haematopoietic malignancies, although 
the authors do not attribute the effects of lower oxygen tensions to the patients' condition. Clearly, the problem is not yet fully resolved and there are a number of possible explanations for this difference, not the least of which may be cell line specificity or culture conditions.

Therefore, this work sets out to thoroughly characterise the standard manual T-flask process for the manual expansion of hMSCs in the laboratory and seeks to establish the likely key process engineering parameters for subsequent bioprocess development. Indeed, this is the approach that was taken by the pharmaceutical industry more than two decades ago to develop large-scale mammalian cell fermentation for the manufacture of therapeu- tic recombinant proteins $[5,15,16]$. Here, two series of experiments were undertaken at different oxygen concentrations (initial incubator gas concentrations giving $100 \% \mathrm{dO}_{2}$ and $20 \% \mathrm{dO}_{2}$ in the culture medium at saturation, hereafter referred to as $100 \% \mathrm{dO}_{2}$ and $20 \% \mathrm{dO}_{2}$ ) and medium exchange protocols $(100 \%, 50 \%$ and $0 \%)$ after $72 \mathrm{~h}$ of in vitro culture of hMSCs over 4 consecutive pas- sages. Unfortunately, as with much of the earlier work in the literature, because of equipment limitations, the change of oxygen concentration in the actual T-flask headspace and medium over time could not be tracked. Initially, a brief study was also undertaken at $10 \% \mathrm{dO}_{2}$ in the medium at saturation, but performance with respect to cell yield was approximately $15 \%$ lower in comparison to that at $20 \% \mathrm{dO}_{2}$ (data not shown), so that further exper iments at this much lower concentration were stopped. In all cases, specific growth rates and yield coefficients with respect to glucose were calculated.

\section{Materials and Methods}

\subsection{Cell growth and conditions}

Human MSCs were isolated from bone-marrow aspirate donated by Lonza (Lonza, Cologne AG) which had been obtained from a single healthy donor after the patient provided informed consent. The local Ethical Committee approved the use of the sample for research. Cells from passage 1 were cryopreserved at a density of $2 \times 10^{6}$ cells. $\mathrm{ml}^{-1}$ in $2 \mathrm{ml}$ of $0.5 \%$ human serum albumin (v/v), $5 \mathrm{ml}$ of dimethylsulphoxide and $93 \mathrm{ml}$ of plasmalyte. All experiments were carried out starting from passage 2. Cells were cultured in $25 \mathrm{ml}$ Dulbecco's Modified Eagle Medium (DMEM; Lonza, UK) supplemented with 10\% (v/v) foetal bovine serum (FBS; Hyclone, Lot\# RUF35869) and 2 mM Lglutamine (Lonza, UK). Cells were grown in monolayer culture at $37^{\circ} \mathrm{C}$ in T75-flasks seeded at an initial density of 5000 cells. $\mathrm{cm}^{-2}$. Duplicate flasks were placed in an incubator with a controlled gas phase (New Brunswick Galaxy 170r incubator), firstly with air supplemented with $5 \% \mathrm{CO}_{2}$ (here 
called $100 \% \mathrm{dO}_{2}$ ); and secondly with $5 \% \mathrm{CO}_{2}$ and $4 \% \mathrm{O}_{2}$ diluted with $\mathrm{N}_{2}$ (here called $20 \% \mathrm{dO}_{2}$ ). The $\mathrm{pH}$ remained between 7.0 - 7.3 throughout the course of the investigation (determined by colorimetric visualisation of the phenol red containing medium and medium sample analysis).

The growth medium was exchanged as appropriate (100\%, 50\% and 0\%) after day 3 of the culture and cells were passaged at day 6 of culture (the usual time found by us for early-stage passage hMSCs to reach confluency). On passage, the hMSCs were washed with phosphate buffered saline (PBS; Lonza, UK) and then incubated for 4 min with trypsin (0.25\%)/EDTA solution (Lonza, UK) to aid cell detachment from the culture plastic. Trypsin was then inactivated by the addition of fresh growth medium equivalent to $3 \mathrm{x}$ the volume of the trypsin solution used for cell detachment. The cell suspension was then centrifuged at $220 \mathrm{~g}$ for $3 \mathrm{~min}$ at room temperature, the supernatant discarded and the remaining pellet re-suspended in an appropriate volume of culture medium. Viable cells were counted and an appropriate number of cells were then re-seeded to a fresh T-flask.

A control condition was setup whereby duplicate T-flasks were left in the gas-phase controlled incubator for the full 6 days of culture. This was done in order to compare the effect, if any, of oxygen concentration fluctuations in the medium arising from the removal of the $\mathrm{T}$ flask from the controlled environment of the incubator to atmospheric conditions for daily medium sampling.

\subsection{Analytical techniques}

A $1 \mathrm{ml}$ sample was taken daily for analysis of $\mathrm{pH}$, [glucose] g/L, [lactate] g/L, and [ammonium] $\mathrm{mmol} / \mathrm{L}$ using a Nova Bioprofile FLEX (USA). Cell counting and viability (via propidium iodide exclusion) was done using a NucleoCounter NC-100 automatic mammalian cell counter (Chemometec, Denmark). Based on the viable cell number and metabolite data, the following parameters were determined:

1. Specific Growth Rate: $\mu=\frac{(\operatorname{Ln}(C x(t)-C x(0)))}{\Delta t}$

Where $\mu=$ specific growth rate $\left(\mathrm{h}^{-1}\right), C x(t)$ and $C x(0)=$ cell numbers at the end and start of exponential growth phase respectively and $t=$ time (h)

2. Doubling time: $t_{d}=\frac{\operatorname{Ln} 2}{\mu}$

Where $t_{d}=$ doubling time $(\mathrm{h})$ and $\mu=$ specific growth rate $\left(\mathrm{h}^{-1}\right)$

3. Population doubling $=3.32 *\left(\log \left(\frac{C x(t)}{C x(0)}\right)\right)$

Where $C x(t)$ and $C x(0)=$ cell numbers at the end and start of exponential growth phase respectively and $t=$ time (h) 
4. Fold Increase $=\frac{C x(f)}{C x(0)}$

Where $C x(f)=$ final cell number at the end of passage and $C x(0)=$ initial cell number

5. Specific metabolite consumption rate: $q_{m e t}=\frac{\mu}{C x(0)} \times \frac{C_{m e t(t)}-C_{m e t}(0)}{e^{\mu t}-1}$

Where $q_{\text {met }}=$ specific metabolite consumption rate, $\mu=$ specific growth rate $\left(\mathrm{h}^{-1}\right), C_{\text {met }}(t)$ and $C_{\text {met }}(0)=$ concentration of metabolite at the start and end of exponential growth phase respectively, $C x(0)=$ cell number at the start of exponential growth phase and $t=$ time (h)

6. Lactate yield from glucose: $Y_{L a c / G l c}=\frac{\Delta[L a c]}{\Delta[G l c]}$

Where $Y_{L a c / G l c}=$ lactate yield from glucose, $\Delta[\mathrm{Lac}]=$ lactate production over specific time period and $\Delta[\mathrm{Glc}]=$ glucose consumption over same time period

\section{3 Immunophenotypic analysis}

Immunophenotypic analysis of the hMSCs was determined by flow cytometry before and after hMSC expansion and was performed using a Beckman Coulter Quanta SC flow cytometer (Beckman Coulter, UK) with excitation at 488nm. Cells were prepared for analysis by centrifuging at $300 \mathrm{~g}$. The supernatant was discarded and the cells were resuspended in flow cytometry stain buffer (R\&D Systems, UK). A panel of mouse anti-human monoclonal antibodies was used to target cell-surface receptors and was prepared in accordance with the manufacturer's instructions. The antibodies selected were primarily in accordance with the Dominici et al. (2006) panel and included CD73-PE, CD105-PerCP, CD29-PE-Cy5, CD45-PE-Cy5, CD34-PE-Cy7 and HLA-DR-PE-Cy5 (BD Biosciences, UK). Cells were incubated with the antibody in the dark at room temperature for 30 min. Associated isotype controls were also prepared for all experimental conditions. A minimum of 10,000 gated (Forward scatter/Side Scatter) events were recorded for each sample and the data was analysed using FlowJo computer software (Treestar Inc, USA). Flourescent gates were set above 95\% of the isotype control.

\subsection{Multilineage potential}

The multi-lineage potential of the cells was ascertained by inducing the samples post-harvest with the StemPro Adipogenesis kit, StemPro Chondrogenesis kit and StemPro Osteogenesis kit. Differentiation media were prepared and used as per the manufacturer's instructions. Briefly, this involved thawing the supplement overnight and adding this to the basal differentiation medium. Cells undergoing adipogenic or osteogenic differentiation were seeded onto a microwell plate at 5,000 cells. $\mathrm{cm}^{-2}$ in growth medium and left in a humidified incubator at $37{ }^{\circ} \mathrm{C}, 5 \% \mathrm{CO}_{2}$ for 3 days, after which the medium was replaced with specific differentiation medium and returned to the incubator. The medium was replaced every 3 days until day 21, at which point the hMSCs undergoing adipogenesis were stained with Oil Red $\mathrm{O}$, and the hMSCs undergoing osteogenesis were stained with 
alkaline phosphatase (ALP) and Von Kossa stains. For chondrogenesis, a hMSC micromass would be formed by generating a cell suspension of $1.6 \times 10^{7}$ cells. $\mathrm{mL}^{-1}$ and then seeding $5 \mu \mathrm{L}$ of this suspension onto microwells. This would be placed into a humidified incubator at $37^{\circ} \mathrm{C}, 5 \% \mathrm{CO}_{2}$ for $2 \mathrm{~h}$, after which, chondrogenic medium would be added. Chondrogenic medium was refreshed every $72 \mathrm{~h}$.

After 21 days, all cell samples were stained with either alkaline phosphatase (ALP) and von Kossa staining (osteogenesis), $0.3 \%$ Oil Red O (adipogenesis) or Alcian Blue (chondrogenesis). For adipogenic differentiation, the medium was aspirated and cells washed with PBS. Cells were fixed with $2 \%(\mathrm{v} / \mathrm{v})$ paraformaldehyde (PFA) for $30 \mathrm{~min}$ at room temperature. Cells were then washed three times with PBS and $0.3 \%(\mathrm{w} / \mathrm{v})$ Oil Red $\mathrm{O}$ solution was added and incubated at room temperature for $60 \mathrm{~min}$. Prior to observing under the microscope, the samples were washed with PBS three times and $1 \mathrm{~mL}$ distilled water was added. Upon final washing, the samples were observed under a Nikon TS-100 light microscope (Nikon, UK).

For chondrogenic differentiation, the medium was aspirated and washed with PBS. The cells were fixed with 2\% PFA for $1 \mathrm{~min}$ at room temperature. Samples were then washed three times with PBS and 1\% (w/v) Alcian Blue solution was added and kept at room temperature for $30 \mathrm{~min}$. Prior to observing under the microscope, the samples were washed with PBS three times and $1 \mathrm{~mL}$ distilled water was added.

For osteogenic differentiation, the medium was aspirated and cells were washed with PBS. The cells were fixed with $10 \%$ cold neutral-buffered formalin for $20 \mathrm{~min}$ at room temperature. Samples were then washed with PBS and kept in distilled water for $15 \mathrm{~min}$ at room temperature before incubating with 4\% (v/v) Napthol AS-MX phosphate alkaline solution in a darkened at room temperature for 45 min. Prior to observing under a microscope, samples were washed three times with distilled water. Distilled water was then removed and samples incubated with $2.5 \%(\mathrm{v} / \mathrm{v})$ silver nitrate solution for 30 min at room temperature. The samples were then washed with distilled water three times before observing under a light microscope.

\section{Results and Discussion}

\section{1 Growth kinetics}

A series of experiments was carried out to evaluate the effect of oxygen concentration and medium exchange strategy on the culture of human bone marrow-derived mesenchymal stem cells (hMSCs). In all cases reproducible data were obtained as indicated by the tight error bars (Figures 1 and 2). For the main programme of work, flasks were cultured for each medium exchange condition $(100 \%, 50 \%$ 
and $0 \%$ after day 3) and each oxygen concentration (nominally $100 \% \mathrm{dO}_{2}$ and $20 \% \mathrm{dO}_{2}$ ) over a period of 4 passages (576 h). During the culture period, daily medium samples were processed for metabolite analysis for all experimental conditions. A control was also investigated to determine what effect, if any, the fluctuations in oxygen concentration arising from daily media sampling would have on the culture. This was achieved by having duplicate T-flasks cultured at $20 \% \mathrm{dO}_{2}$ which were not removed from this environment until day 6 of each passage. hMSC expansion was monitored by measurement of viable cell number after each passage. From this data, cumulative viable cell number and cumulative population doublings were calculated (Figure 1) for each set of conditions in addition to specific growth rate $\left(\mathrm{h}^{-1}\right)$, fold increase and doubling time (h) (Figs. 3A, 3B and 3C).

Before proceeding further, it is useful to consider the actual dissolved oxygen concentration in the medium in the T-flask since the number of cells consuming oxygen has been measured under different conditions. The oxygen concentration in the medium can be determined from the equation:

$$
N_{\text {cell }} O_{c}=k_{L} A\left(C_{L}^{*}-C_{L}\right)=k_{L} A \Delta C
$$

where $N_{\text {cell }}$ is number of cells in the T-flask (here up to about $3 \times 10^{6}$ cells.flask $^{-1}$ ), $O_{c}$ is the specific oxygen consumption rate of the cell, $A$ is the medium/gas surface area in the T-flask $\left(75 \mathrm{~cm}^{2}\right), k_{L}$ is the mass transfer coefficient and $C_{L}^{*}$ and $C_{L}$ are the oxygen concentration in equilibrium with the head space gas and in the liquid phase respectively. Many of these parameters are not known precisely. However, sufficiently accurate estimates can be made to give an indication of how much the liquid phase oxygen concentration that the cells experience on the base of the T-flask is likely to fall due to their consumption of oxygen compared to that due to the concentration in the head space.

An approximate specific oxygen uptake rate for the cells can be obtained from the work of Pattappa et al. [18] on human MSC cells as $9.8 \times 10^{-11} \mathrm{mmol}^{-c e} \mathrm{Il}^{-1} \cdot \mathrm{h}^{-1}$ [15]; $\mathrm{k}_{\mathrm{L}}$ can be estimated from the work of Randers-Eichhorn et al. [19]. The latter found in T-flasks growing animal cells that the rate of oxygen transfer into the medium at depths of $4 \mathrm{~mm}$ or less was essentially governed by molecular diffusion, i.e., $\mathrm{k}_{\mathrm{L}}=\mathrm{D} / \mathrm{x}$ where $\mathrm{D}$ is the diffusivity of oxygen and $\mathrm{x}$ is the depth of medium above the cells, here 1 $\mathrm{mm}$. The diffusivity in the medium depends on both its composition and temperature. The former is not known precisely but the sensitivity to water, salt and glucose solutions at $20{ }^{\circ} \mathrm{C}$ is rather weak [20]; and whilst the effect of temperature is quite substantial, the value at the cultivation temperature is not given [http://compost.css.cornell.edu/oxygen/oxygen.diff.water.html]. A value of $0.11 \mathrm{~cm}^{2} . \mathrm{h}^{-1}$ is assumed based on the above references to give $\mathrm{k}_{\mathrm{L}}=1.1 \mathrm{~cm} \cdot \mathrm{h}^{-1}$. Thus, from Eq 7, $\Delta C=3.36 \times 10^{-6}$ mmol.cm ${ }^{-3}=3.36 \times 10^{-3}$ mmol. $\mathrm{L}^{-1}$. 
Randers-Eichhorn et al. [19] also cultivated CHO cells in T-flasks to a cell density of $\sim 2 \times 10^{6}$ cells. $\mathrm{mL}^{-1}$ in a $350 \mathrm{~mL}$ T-flask with a specific oxygen uptake rate of $\sim 1.3 \times 10^{-10} \mathrm{mmol} \mathrm{O}_{2}$. $\mathrm{cell}^{-1}$. $\mathrm{hr}^{-1}$ [16] (similar to values up to $2 \times 10^{-10} \mathrm{mmol} \mathrm{O}_{2} \cdot \mathrm{cell}^{-1} \cdot \mathrm{hr}^{-1}$ found by Miller et al. (1988) [21]). Under these conditions, where the overall oxygen demand of the CHO cells will be much greater than in this work (and indeed significant oxygen depletion was measured in the medium), they found that the head space oxygen concentration was essentially constant and equal to that in the incubator whether the T flask caps were cracked open or completely closed. It seems reasonable to assume here therefore that the headspace oxygen concentration in the T-flask was the same as in the incubator. It is assumed therefore that an atmospheric air concentration of $\sim 20 \% \mathrm{O}_{2}$ in the incubator will give the same concentration in the headspace of the T-flask and an equilibrium concentration in the media of $\sim 0.2$ mmol. $\mathrm{L}^{-1}$ at $35^{\circ} \mathrm{C}[22]$.

Thus, even with assumptions made here, it is clear that since $\Delta C_{L}=\sim 3.36 \times 10^{-3} \mathrm{mmol}_{\mathrm{L}}^{-1}<<C_{L}^{*}$, the oxygen concentration in the medium at the base of the T-flask, $C_{L}$ (where the cells grow) will essentially be the same as that at the gas/medium interface, $C_{L}^{*}$, which is, by definition, in equilibrium with that in the headspace. Since the headspace and the incubator concentrations are the same too, it is therefore correct to call the concentration in the medium $100 \%$ or $20 \% \mathrm{dO}_{2}$ for the two incubator oxygen concentrations used in this work.

Differences with respect to cumulative viable cell number and population doublings were observed between each different $\mathrm{dO}_{2}$, with $100 \% \mathrm{dO}_{2}$ yielding a greater number of viable cells for each medium condition than the $20 \% \mathrm{dO}_{2}$. Flasks cultured under $100 \% \mathrm{dO}_{2}$ and subjected to a $100 \%$ medium exchange gave a cumulative total of greater than $12.5 \times 10^{6}$ viable cells over a period of four passages, whilst flasks subjected to the same medium exchange routine but cultured under $20 \% \mathrm{dO}_{2}$ yielded a cumulative total of less than $10.0 \times 10^{6}$ cells. This was similarly reflected with the $50 \%$ and $0 \%$ medium exchange conditions where the cumulative numbers of viable cells were higher when cultured under $100 \% \mathrm{dO}_{2}$ as opposed to those cultured under $20 \% \mathrm{dO}_{2}$. As a result, the population doublings for the flasks cultured under the higher $\mathrm{dO}_{2}$ were also greater (12.2, 11.5, 9.7 population doublings for $100 \%, 50 \%$ and $0 \%$ medium exchange conditions respectively), than those cultured under the lower $\mathrm{dO}_{2}$ (11.5, 10.7 and 8.7 population doublings for $100 \%, 50 \%$ and $0 \%$ medium exchange conditions respectively). The control flasks which remained in the $20 \% \mathrm{dO}_{2}$ environment for the duration of each passage showed no significant difference in terms of viable cell number in comparison to the $0 \%$ medium exchange condition cultured at the $20 \% \mathrm{dO}_{2}$ condition, i.e the cell yield values consistently fell within the range of the error bars for the $0 \%$ medium exchange at $20 \%$ $\mathrm{dO}_{2}$. Importantly, this illustrates that variations in cell yield did not arise from any $\mathrm{dO}_{2}$ fluctuations in the medium as a result of daily sampling. Figure 1 also illustrates the effect of varying the percentage 
medium exchange on cell yield, with the $100 \%$ medium exchange yielding the largest cumulative number of viable cells and population doublings in comparison to the $50 \%$ and $0 \%$ medium exchange conditions irrespective of the $\mathrm{dO}_{2}$ concentration.

In general, it was found that the specific growth rate, doubling time and fold increase mirrored the trends found with the cumulative viable cell number and population doubling data, with the $100 \% \mathrm{dO}_{2}$ and $100 \%$ medium exchange conditions having the greatest impact on cell yield and growth kinetics. The findings here are in agreement with others [14], who found that a lower $\mathrm{dO}_{2}$ tension restricted the proliferative capacity of hMSCs in comparison with hMSCs cultured at $20-21 \% \mathrm{v} / \mathrm{v} \mathrm{O}_{2}$ in the gas phase $\left(100 \% \mathrm{dO}_{2}\right)$. Importantly, the results presented here are in contrast to other work [10, 23-25] suggesting improved hMSC proliferation kinetics when cultured under low dissolved oxygen conditions. It is likely that such differences are in part due to the innate donor-to-donor variability of cells, as well as differences in culture conditions [26], including, but not limited to, the use of different undefined, serum-based media and initial cell passage number. Further, cell passage number can have a significant effect on hMSC quality [25] with respect to proliferation, phenotype and differentiation potential. Indeed, such an effect can also be found from the data presented here where there is an overall decrease in the specific growth rate and an increase in the doubling times as passage number increases for all medium exchange and $\mathrm{dO}_{2}$ conditions (Fig 3). Despite the cells being cultured over only four passages (passages 3-7 of actual cell age, identified as passages 1-4 in this investigation), the cell growth kinetics are affected and will only be further affected as passage number increases. There were, however, no discernible effects on phenotype or differentiation potential (as discussed later).

The data presented here raises valid questions regarding the optimal conditions for the expansion of hMSCs. Many groups who have investigated the culture of hMSCs at lower oxygen concentrations, including Lavrentieva et al. 2010 [25] and Dos Santos et al. 2010 [24], have done so on the basis that such an environment is similar to that experienced by the hMSCs in vivo. Whilst this is undisputed, it must also be recognised that in vivo, hMSCs account for few of the cells in the bone marrow niche, ranging from 1 in 10,000 marrow cells in a newborn to 1 in 100,000 for teens and 1 in 2,000,000 for those aged 80 [28]. From a bioprocessing perspective, the focus would firmly be on optimising culture conditions to ensure maximum expansion, whilst retaining critical to quality features. Therefore, it may be argued that replicating in vivo conditions with respect to oxygen concentration may not necessarily equate with the optimum conditions for hMSC expansion given that at the low oxygen concentrations within the bone marrow niche, there is a very small number of hMSCs present. It could also be suggested therefore that in vivo expansion of hMSCs does not occur in the hypoxic 
environments of the bone marrow niche, but rather either en route or at the actual site of injury, which are likely to be under a higher oxygen concentration [29] than that of bone marrow.

When looking at the effects of oxygen concentration on other stem cells types, just as in the MSCbased literature, there is conflicting evidence about the impact of low oxygen conditions on the proliferation of adipose stem cells [30-32], hematopoietic stem cells and progenitor cells [33-39]. Indeed, the effect of low oxygen tension on haematopoietic stem and progenitor cells, which share the same bone marrow niche as hMSCs, is an area of research that has been investigated over a number of years, with studies dating back to the 1970s [40, 41]. As early as 1986, conflicting reports were emerging regarding the effect of low oxygen concentration on these cells [39] in that all colony types investigated (CFU-mix, BFU-E, CFU-E, and CFU$\mathrm{GM})$ demonstrated enhanced growth at low oxygen conditions $\left(5 \% \mathrm{O}_{2}\right)$ in comparison to atmospheric oxygen conditions [39]. In the same year it was reported that the growth of haematopoietic progenitor cells from cord blood was enhanced at a low oxygen concentration $\left(5 \% \mathrm{O}_{2}\right)$ only for the early stage of the culture (weeks $\left.0-4\right)$ and that by week 5 , the growth was supe- rior at atmospheric conditions [36]. Moreover, it was demonstrated that at atmospheric conditions, CFU-GM were maintained for more than 12 weeks; in comparison, no CFU-GM were detected after week 8 at the low oxygen concentration [36]. In a similar study but with the inclusion of an irradiated bone marrow stromal layer [38], it was reported that growth of haematopoietic stem and progenitor cells was superior in low oxygen conditions $\left(5 \% \mathrm{O}_{2}\right)$ in comparison to atmospheric oxygen conditions, although the effects were not as pronounced [38]. Meanwhile it was found [33] that human bone marrow derived $\operatorname{lin}^{-C D} 34^{+}$cells grown for 4 days in low oxygen $\left(1.5 \% \mathrm{O}_{2}\right.$ in the incubator) culture conditions exhibited a lower fold expansion ( 3.8 fold) compared to those cultured in $20 \% \mathrm{O}_{2},(\sim 2.9$ fold $)$. Indeed, a specific subpopulation of lin $^{-} \mathrm{CD}_{34}{ }^{+} \mathrm{CD} 38^{-}$cells responded in the opposite manner, with an approximately 2.5 fold expansion under the low oxygen conditions compared with 1.5 fold expansion under atmospheric conditions, indicating that some of the conflicting data may be due to differences in the cell populations studied [33].

Given this disparity in the literature regarding the effect of low oxygen concentration for haematopoietic, adipose and mesenchymal stem cells, it is clear that further work is required to provide a definitive answer as to the exact effect of oxygen concentration on the culture of such cell types. As suggested by others [42], a standardised experimental approach would certainly aid in this endeavour and would further our understanding of how various stem cells respond to a range of oxygen concentrations [42], as would attempts to mimic the stem cell niche ex vivo, where the oxygen concentration can be configured to match the 
physiological concentration [23]. Furthermore, we agree with the attempts to establish clear nomenclature with respect to oxygen concentrations both in vitro and in vivo as suggested by others [43,44], however it is our contention that the pre-existing nomenclature in biochemical engineering be employed where oxygen concentration is considered in terms of the nominal $\% \mathrm{dO}_{2}$ with respect to saturation in the liquid medium, thereby reducing any ambiguity.

Recently, the wealth of studies on hypoxia, haematopoietic stem cells and the role of HIF expression in the cellular response to hypoxia have been extensively reviewed and we would direct the readers to this work for more in- depth analysis [45]. Elsewhere it has been suggested that slow-cycling haematopoietic stem cells are more likely to remain in the lower oxygen areas of the niche, further away from local vasculature, whilst fast-cycling haematopoietic stem cells are more likely to remain closer to blood vessels [29]. It is argued that this may prove advantageous for the slow-cycling haematopoietic stem cells as they may avoid the effects of oxidative stress, which can result in DNA damage due to the formation of reactive oxygen species [46]; this hypothesis was strengthened further when it was found that mouse embryonic fibroblasts cultured at atmospheric oxygen conditions developed more mutations and senesced faster than those cultured at 3\% oxygen conditions [47]. Whilst haematopoietic stem cells are a different cell type than bone marrow MSCs, given that they share the bone marrow niche, it is interesting to note in passing that low oxygen concentrations are more favorable for slow-cycling haematopoietic stem cells than higher oxygen concentrations

\subsection{Metabolite analysis}

Reproducible measurements of key metabolites, glucose, lactate and ammonium, were obtained daily to ascertain the consumption of glucose and production of lactate and ammonium during culture (Figure 2). In general, the concentration of glucose was lower and the concentrations of lactate and ammonium was greater by the end of the passage when no medium exchange was performed in comparison to flasks which had a $50 \%$ or $100 \%$ medium exchange after $72 \mathrm{~h}$. This effect was greater when the cells were cultured under $20 \% \mathrm{dO}_{2}$. The medium exchange in hMSC culture plays an important role in not only replenishing the cells with key nutrients such as glucose, but also serves to avoid accumulation of inhibitory waste products such as lactate and ammonium (Figure 2). The lower cell yield obtained with the $0 \%$ medium exchange in comparison to the $50 \%$ and $100 \%$ medium exchange can therefore be attributed to the build up of inhibitory waste products and a lower glucose level, resulting in an effect on cell proliferation.

All experimental conditions follow the same trend with respect to metabolite consumption/production and correlate with increasing cell number; the level of glucose decreases during culture whilst the 
levels of ammonium and lactate increase (Figure 2). The metabolite data, in conjunction with cell growth kinetics, allows for the calculation of the specific glucose consumption rate (pmol cell ${ }^{-1}$ day $^{-1}$ ), specific lactate production rate (pmol cell ${ }^{-1}$ day $^{-1}$ ) and yield of lactate from glucose (mol.mol ${ }^{-1}$ ) (Figures 3D, 3E and 3F). When comparing the metabolite data for both $\mathrm{dO}_{2}$ conditions irrespective of medium exchange condition, it is evident that significantly more glucose is consumed whilst more lactate and ammonium is produced when cultured under $20 \% \mathrm{dO}_{2}$ despite the $20 \% \mathrm{dO}_{2}$ condition yielding fewer cells. However the lactate and ammonium concentrations did not reach values which may be considered to inhibit cell growth, which have been determined experimentally for hMSCs as greater than $20 \mathrm{mmol} / \mathrm{L}$ and $2 \mathrm{mmol} / \mathrm{L}$ for ammonium respectively [48]. The increase in glucose consumed and lactate produced for cells cultured at $20 \% \mathrm{dO}_{2}$ is reflected in the glucose consumption and lactate production rates where there is a consistent significant difference between the $\mathrm{dO}_{2}$ tensions for all medium exchange conditions (Figure 3). These findings are consistent with in vitro studies investigating the effect of oxygen tension on hMSCs [24,25]. Despite contrasting results of $\mathrm{dO}_{2}$ on hMSC proliferation, there is similarity in the increased consumption of nutrients and increased production of inhibitory waste products. The increase in consumption of glucose and production of ammonium and lactate indicate that there are cellular responses due to the stress of a low oxygen environment. Such an environment initiates the usage of alternative intracellular pathways, thereby impacting cellular metabolism which may impact proliferation. It is believed that under lower dissolved oxygen conditions, mammalian cells adapt by activating various cellular pathways including gene-regulation by so called "hypoxia"-inducible factors and mTOR signalling [49]. The intracellular responses to low oxygen-induced stress results in cell cycle arrest which can impact proliferation of hMSCs as the cells attempt to maintain homeostasis and enter a quiescent state [14]. Despite the lower cell yields and increased glucose and lactate production rates, the cells cultured at both dissolved oxygen conditions generally gave values for yield of lactate from glucose ( $\mathrm{Y}_{\text {lactate/glucose }}$ ) in excess of $\sim 2 \mathrm{~mol}^{\mathrm{mol}}{ }^{-1}$. Theoretically only $\sim 2$ mole of lactate can be obtained from each mole of glucose [32]. Therefore, a $Y_{\text {lactate/glucose }}$ value of $>2$ suggests lactate being acquired through the catabolism of other carbon sources, such as glutamine or other amino acids [6], which would appear to be the case for most of the experimental culture conditions studied here.

\subsection{Immunophenotype analysis}

In order to determine the quality of the hMSCs and to identify whether there had been any change following expansion under both dissolved oxygen tensions, immunophenotype analysis was performed using flow cytometry before the cells were seeded for passage 1 of the experiment and subsequently at the end of passage 4. For all experimental conditions both before and after the 
investigation, > 95\% of the cell population were positive for CD29, CD73 and CD105 (markers which are commonly associated with multi-potent hMSCs) and $<5 \%$ of the cell population were positive for CD45, CD34 and HLA-DR (markers used as negative controls) (Figure 4, Tables 1A and 1B). As such, the effect of medium exchange and $\mathrm{dO}_{2}$ had no discernible effect on the immunophenotype of the hMSCs. However, according to the ISCT's criteria for defining hMSCs, >2\% HLA-DR expression is indicative of an activated MSC population. Our results indicate that before the first experimental passage $(0 \mathrm{~h})$, a small percentage of our MSC population ( 4.5\%) is activated, however, this value does not increase to $5 \%$ for any experimental culture condition after 4 passages.

\subsection{Multilineage potential}

The multilineage potential of the hMSCs was demonstrated by inducing differentiation towards the osteogenic, adipogenic and chondrogenic lineages. After 14 days in lineage-specific differentiation media, samples of all experimental conditions were found to be positive for alkaline phosphatase and von Kossa staining demonstrating osteogenic differentiation capability; positive for Oil Red O staining demonstrating adipogenic differentiation capability and positive for Alcian Blue staining demonstrating chondrogenic differentiation capability (Figure 5). As with the immunophenotypic analysis, the effect of medium exchange and $\mathrm{dO}_{2}$ did not affect the differentiation capacity of the hMSCs.

\section{Concluding remarks}

It is recognised that today, hMSC culture is at a crucial junction similar to that of CHO cell culture 20-30 years ago. Measurements taken during hMSC culture are usually restricted only to cell number, viability, confluency and those related to functionality. To realise the potential of hMSC-based therapeutics, it is incumbent that, where possible, quantitative measurements are obtained to provide an accurate reflection of culture conditions and as a means for process engineering development (e.g. the accurate calculation of nutrient feed rates for perfusion culture). Further, the data presented here raises valid questions regarding the optimal conditions for the expansion of hMSCs, given in vivo conditions (within the bone marrow niche), the oxygen concentration is considered "hypoxic", yet it is recognised that there are very few hMSCs present [28].

It was found that $20 \% \mathrm{dO}_{2}$ impacts human MSC proliferation resulting in lower cell yields in comparison to hMSCs cultured under $100 \% \mathrm{dO}_{2}$ conditions. This is in contrast to other studies which demonstrate an increase in hMSC yield under lower oxygen concentrations and the hypothesis that hMSC proliferation would increase under physiologically similar $\mathrm{dO}_{2}$ levels. That there is disparity in the literature with regards to the effect of oxygen concentration on hMSC proliferation highlights the 
variability that exists between cell lines and is likely to be a result of donor-to-donor variability and/or medium formulation.

The data also highlight the importance of implementing a quantitative approach and measuring as many parameters as possible in an attempt to understand internal cellular mechanisms and processes. Whilst the hMSC yield decreased at lower oxygen concentrations, the rate of glucose consumption and lactate and ammonium production increased, therefore suggesting different metabolic pathways being employed as the hMSCs adapt to low oxygen conditions. The medium exchange quantity was found to also have an effect cell proliferation and metabolism, with a $100 \%$ medium exchange resulting in the greatest cumulative viable cell number over the series of four passages, followed by the 50\% which was slightly lower and then, significantly lower, $0 \%$ respectively. Based on the metabolite data, this is likely to be due to the accumulation of inhibitory concentrations of lactate and ammonium or other unknown waste products. There was a clear correlation between the concentration of these known metabolites and the percentage of medium exchange performed, whereby the lower percentage of medium exchange performed, the higher the concentration of both ammonium and lactate at the end of each passage. This demonstrates that where possible, a complete medium exchange would aid cell proliferation through the replacement of lost nutrients, and more importantly perhaps through the removal of inhibitory waste products. Indeed this would suggest the development of perfusion culture at the larger scale. Importantly, despite the variation in experimental conditions, there was no discernible effect on cell quality as the cells retained both their immunophenotype and multi-lineage differentiation capability throughout.

\section{Acknowledgements}

The authors would like to acknowledge the Biotechnology and Biological Sciences Research Council (BBSRC; UK) Bioprocessing Research Industries Club (BRIC), the Engineering and Physical Sciences Research Council (EPSRC; UK) and Lonza GmbH (Cologne, Germany) for their financial support.

The authors declare no commercial or financial conflict of interest

\section{References}

[1] Hewitt, C. J., Lee, K., Nienow, A. W., Thomas, R. J. et al, Expansion of human mesenchymal stem cells on microcarriers. Biotechnol. Lett. 2011, 33, 2325-2335.

[2] Baksh, D., Song, L., Tuan, R. S., Adult mesenchymal stem cells: characterization, differentiation, and application in cell and gene therapy. J. Cell. Mol. Med. 2004, 8, 301-316. 
[3] Jackson, L., Jones, D. R., Scotting, P., Sottile, V., Adult mesenchymal stem cells: differentiation potential and therapeutic applications. J. Postgrad. Med. 2007, 53, 121-127.

[4] Brindley, D., Mason, C., Human embryonic stem cell therapy in the post-Geron era. Regen. Med. 2012, 7, 17-18.

[5] Doran, P. M., Bioprocess Engineering Principles, Academic Press, San Diego 1995.

[6] Glacken, M. W., Catabolic Control of Mammalian Cell Culture. Nat.

Biotech. 1988, 6, 1041-1050.

[7] Nienow, A. W., Reactor engineering in large scale animal cell culture.

Cytotechnology 2006, 50, 9-33.

[8] Chow, D. C., Wenning, L. A., Miller, W. M., Papoutsakis, E. T., Modeling $\mathrm{pO}_{2}$ distributions in the bone marrow hematopoietic compartment. I. Krogh’s model. Biophys. J. 2001, 81, 675684.

[9] Chow, D. C., Wenning, L. A., Miller, W. M., Papoutsakis, E. T., Modeling $\mathrm{pO}_{2}$ distributions in the bone marrow hematopoietic compartment. II. modified Kroghian models. Biophys. J. 2001, 81, 685-696.

[10] Grayson, W. L., Zhao, F., Bunnell, B., Ma, T., Hypoxia enhances proliferation and tissue formation of human mesenchymal stem cells. Biochem. Biophys. Res. Commun. 2007, 358, 948-953.

[11] Hung, S. P., Ho, J. H., Shih, Y. V., Lo, T., Lee, O. K., Hypoxia promotes proliferation and osteogenic differentiation potentials of human mesenchymal stem cells. J. Orthop. Res. 2012, 30, 260-266.

[12] Estrada, J. C., Albo, C., Benguría, A., Dopazo, A. et al., Culture of human mesenchymal stem cells at low oxygen tension improves growth and genetic stability by activating glycolysis. Cell Death Dif-fer. 2011, 19, 743-755.

[13] Fehrer, C., Brunauer, R., Laschober, G., Unterluggauer, H. et al., Reduced oxygen tension attenuates differentiation capacity of human mesenchymal stem cells and prolongs their lifespan. Aging Cell 2007, 6, 745-757.

[14] Holzwarth, C., Vaegler, M., Gieseke, F., Pfister, S. M. et al., Low physiologic oxygen tensions reduce proliferation and differentiation of human multipotent mesenchymal stromal cells. BMC Cell Biol. 2010, 11,11 .

[15] Mason, C., Hoare, M., Regenerative medicine bioprocessing: the need to learn from the experience of other fields. Regen. Med. 2006, $1,615-623$.

[16] Jones, S., McKee, S. D., Levine, H. L., Emerging challenges in cell therapy manufacturing. Bioprocess Int. 2012, 10, 4-7. 
[17] Dominici, M., Le Blanc, K., Mueller, I., Slaper-Cortenbach, I. et al., Minimal criteria for defining multipotent mesenchymal stromal cells. The International Society for Cellular Therapy position statement. Cytotherapy, 2006, 8, 315-7.

[18] Pattappa, G., Heywood, H. K., de Bruijn, J. D., Lee, D. A., The metabolism of human mesenchymal stem cells during proliferation and differentiation. J. Cell. Physiol. 2011, 226, 2562-2570.

[19] Randers-Eichhorn, L., Bartlett, R. A., Frey, D. D., Rao, G., Noninvasive oxygen measurements and mass transfer considerations in tissue culture flasks. Biotechnol. Bioeng. 1996, 51, 466-478.

[20] Jamnongwong, M., Loubiere, K., Dietrich, N., Hébrard, G., Experimental study of oxygen diffusion coefficients in clean water containing salt, glucose or surfactant: Consequences on the liquid-side mass transfer coefficients. Chem. Eng. J. 2010, 165, 758-768.

[21] Miller, W. M., Wilke, C. R., Blanch, H. W., Transient responses of hybridoma metabolism to changes in the oxygen supply rate in continuous culture. Bioprocess Eng. 1988, 3, 103-111.

[22] Bailey, J. E., Ollis, D. F., Biochemical Engineering Fundamentals, McGraw-Hill, New York 1986.

[23] Dellatore, S. M., Garcia, A. S., Miller, W. M., Mimicking stem cell niches to increase stem cell expansion. Gurr. Opin. Biotechnol. 2008,

19, 534-540.

[24] Dos Santos, F., Andrade, P. Z., Boura, J. S., Abecasis, M. M. et al., Ex vivo expansion of human mesenchymal stem cells: a more effective cell proliferation kinetics and metabolism under hypoxia. J. Cell. Physiol. 2010, 223, 27-35.

[25] Lavrentieva, A., Majore, I., Kasper, C., Hass, R., Effects of hypoxic culture conditions on umbilical cord-derived human mesenchymal stem cells. Cell Commun. Signal 2010, 8, 18.

[26] Sotiropoulou, P. A., Perez, S. A., Salagianni, M., Baxevanis, C. N., Papamichail, M., Characterization of the optimal culture conditions for clinical scale production of human mesenchymal stem cells. Stem Cells 2006, 24, 462-471.

[27] Wagner, W., Horn, P., Castoldi, M., Diehlmann, A. et al., Replicative senescence of mesenchymal stem cells: a continuous and organized process. PLoS ONE 2008, 3, e2213.

[28] Caplan, A. I., Adult mesenchymal stem cells for tissue engineering versus regenerative medicine. J. Cell. Physiol. 2007, 213, 341-347.

[29] Mohyeldin, A., Garzon-Muvdi, T., Quinones-Hinojosa, A., Oxygen in stem cell biology: a critical component of the stem cell niche. Cell Stem Cell 2010, 7, 150-161.

[30] Thangarajah, H., Vial, I. N., Chang, E., El-Ftesi, S. et al., IFATS collection: adipose stromal cells adopt a proangiogenic phenotype under the influence of hypoxia. Stem Cells 2009, 27, 266-274. 
[31] Follmar, K. E., Decroos, F. C., Prichard, H. L., Wang, H. T. et al., Effects of glutamine, glucose, and oxygen concentration on the metabolism and proliferation of rabbit adipose-derived stem cells. Tissue Eng.2006, 12, 3525-3533.

[32] Khan, W. S., Adesida, A. B., Hardingham, T. E., Hypoxic conditions increase hypoxiainducible transcription factor 2alpha and enhance chondrogenesis in stem cells from the infrapatellar fat pad of osteoarthritis patients. Arthritis Res. Ther. 2007, 9, R55.

[33] Danet, G. H., Pan, Y., Luongo, J. L., Bonnet, D. A., Simon, M. C., Expansion of human SCID-repopulating cells under hypoxic conditions. J. Clin. Invest. 2003, 112, 126-135.

[34] Eliasson, P., Rehn, M., Hammar, P., Larsson, P. et al., Hypoxia mediates low cell-cycle activity and increases the proportion of long- term-reconstituting hematopoietic stem cells during in vitro cul- ture. Exp. Hematol. 2010, 38, 301-310.e302.

[35] Ivanovic, Z., Dello Sbarba, P., Trimoreau, F., Faucher, J. L., Praloran, V., Primitive human HPCs are better maintained and expanded in vitro at 1 percent oxygen than at 20 percent. Transfusion (Paris)2000, 40, 1482-1488.

[36] Smith, S., Broxmeyer, H. E., The influence of oxygen tension on the long-term growth in vitro of haematopoietic progenitor cells from human cord blood. Br. J. Haematol. 1986, 63, 29-34.

[37] Koller, M. R., Bender, J. G., Miller, W. M., Papoutsakis, E. T., Reduced oxygen tension increases hematopoiesis in long-term culture of human stem and progenitor cells from cord blood and bone marrow. Exp. Hematol. 1992, 20, 264-270.

[38] Koller, M. R., Bender, J. G., Papoutsakis, E. T., Miller, W. M., Beneficial effects of reduced oxygen tension and perfusion in long-term hematopoietic cultures. Ann. N. Y. Acad. Sci. 1992, 665, 105-116.

[39] Maeda, H., Hotta, T., Yamada, H., Enhanced colony formation of human hemopoietic stem cells in reduced oxygen tension. Exp. Hematol. 1986, 14, 930-934.

[40] Murphy, M. J., Jr., Lord, B. I., Hematopoietic stem cell regulation. I. Acute effects of hypoxic-hypoxia on CFU kinetics. Blood 1973, 42, 81-87.

[41] Lord, B. I., Murphy, M. J., Jr., Hematopoietic stem cell regulation. II. Chronic effects of hypoxic-hypoxia on CFU kinetics. Blood 1973, 42, 89-98.

[42] Abdollahi, H., Harris, L. J., Zhang, P., McIlhenny, S. et al., The role of hypoxia in stem cell differentiation and therapeutics. J. Surg. Res.2011, 165, 112-117.

[43] Ivanovic, Z., Hypoxia or in situ normoxia: The stem cell paradigm. J. Cell. Physiol. 2009, 219, 271-275.

[44] Guitart, A. V., Hammoud, M., Dello Sbarba, P., Ivanovic, Z., Praloran, V., Slowcycling/quiescence balance of hematopoietic stem cells is related to physiological gradient of oxygen. Exp. Hematol. 2010, 38, 
847-851.

[45] Eliasson, P., Jonsson, J. I., The hematopoietic stem cell niche: low in oxygen but a nice place to be. J. Cell. Physiol. 2010, 222, 17-22.

[46] Cipolleschi, M. G., Dello Sbarba, P., Olivotto, M., The role of hypoxia in the maintenance of hematopoietic stem cells. Blood 1993, 82, 2031-2037.

[47] Busuttil, R. A., Rubio, M., Dolle, M. E., Campisi, J., Vijg, J., Oxygen accelerates the accumulation of mutations during the senescence and immortalization of murine cells in culture. Aging Cell 2003, 2, 287-294.

[48] Schop, D., Janssen, F. W., van Rijn, L. D., Fernandes, H. et al., Growth, metabolism, and growth inhibitors of mesenchymal stem cells. Tissue Eng. Part A 2009, 15, 1877-1886.

[49] Majmundar, A. J., Wong, W. J., Simon, M. C., Hypoxia-Inducible Fac- tors and the Response to Hypoxic Stress. Mol. Cell 2010, 40, 294-309.

[50] Schop, D., van Dijkhuizen-Radersma, R., Borgart, E., Janssen, F. W., et al, Expansion of human mesenchymal stromal cells on microcar- riers: growth and metabolism. J. Tissue Eng. Regen. Med. 2010, 4, 131-140. 
Table 1. (A) Percentage expression of cell surface markers before passage $1(0 \mathrm{~h})$ and at the end of passage 4 (576 h) for all medium exchange conditions at $100 \% \mathrm{dO}_{2}$ at saturation. Mean value \pm range of data, in all cases 10,000 events were measured for duplicate samples. (B) Percentage expression of cell surface markers before passage $1(0 \mathrm{~h})$ and at the end of passage $4(576 \mathrm{~h})$ for all medium exchange conditions cultured at $20 \% \mathrm{dO}_{2}$ at saturation. Mean value \pm range of data, in all cases 10,000 events were measured for duplicate samples.

\begin{tabular}{lcccc}
\hline A Immunophenotype & \multicolumn{1}{c}{ 100\% medium } & 50\% medium & 0\% medium \\
\hline & $0 \mathrm{~h}$ & $576 \mathrm{~h}$ & $576 \mathrm{~h}$ & $576 \mathrm{~h}$ \\
\hline CD29 & $98.4 \pm 0.3$ & $98.2 \pm 0.4$ & $98.7 \pm 0.6$ & $99.2 \pm 0.3$ \\
CD73 & $97.1 \pm 0.1$ & $97.1 \pm 0.4$ & $96.4 \pm 0.1$ & $98.2 \pm 0.2$ \\
CD105 & $99.8 \pm 0.1$ & $99.3 \pm 0.2$ & $97.6 \% \pm 0.4$ & $98.9 \pm 0.2$ \\
CD34 & $0.97 \pm 0.02$ & $1.5 \pm$ & $2.2 \pm 0.4$ & $1.2 \pm 0.4$ \\
CD45 & $0.08 \pm 0.02$ & $0.09 \pm 0.01$ & $0.18 \pm 0.06$ & $0.45 \pm 0.1$ \\
HLA-DR & $4.68 \pm 0.09$ & $4.44 \pm 0.4$ & $4.69 \pm 0.3$ & $4.42 \pm 0.4$ \\
\hline
\end{tabular}

\begin{tabular}{lcccc}
\hline B Immunophenotype & \multicolumn{1}{c}{ 100\% medium } & 50\% medium & 0\% medium \\
\hline & $0 \mathrm{~h}$ & $576 \mathrm{~h}$ & $576 \mathrm{~h}$ & $576 \mathrm{~h}$ \\
\hline CD29 & $98.4 \pm 0.3$ & $97.3 \pm 0.4$ & $99.1 \pm 0.2$ & $97.9 \pm 0.3$ \\
CD73 & $97.1 \pm 0.1$ & $96.4 \pm 0.2$ & $95.6 \pm 0.4$ & $97.9 \pm 0.3$ \\
CD105 & $99.8 \pm 0.1$ & $98.9 \pm 0.1$ & $99.8 \% \pm 0.1$ & $95.9 \pm 0.6$ \\
CD34 & $0.97 \pm 0.02$ & $0.99 \pm 0.03$ & $0.95 \pm 0.03$ & $0.98 \pm 0.04$ \\
CD45 & $0.08 \pm 0.02$ & $0.10 \pm 0.02$ & $0.11 \pm 0.03$ & $0.09 \pm 0.00$ \\
HLA-DR & $4.68 \pm 0.09$ & $4.29 \pm 0.1$ & $4.92 \pm 0.2$ & $4.48 \pm 0.2$ \\
\hline
\end{tabular}



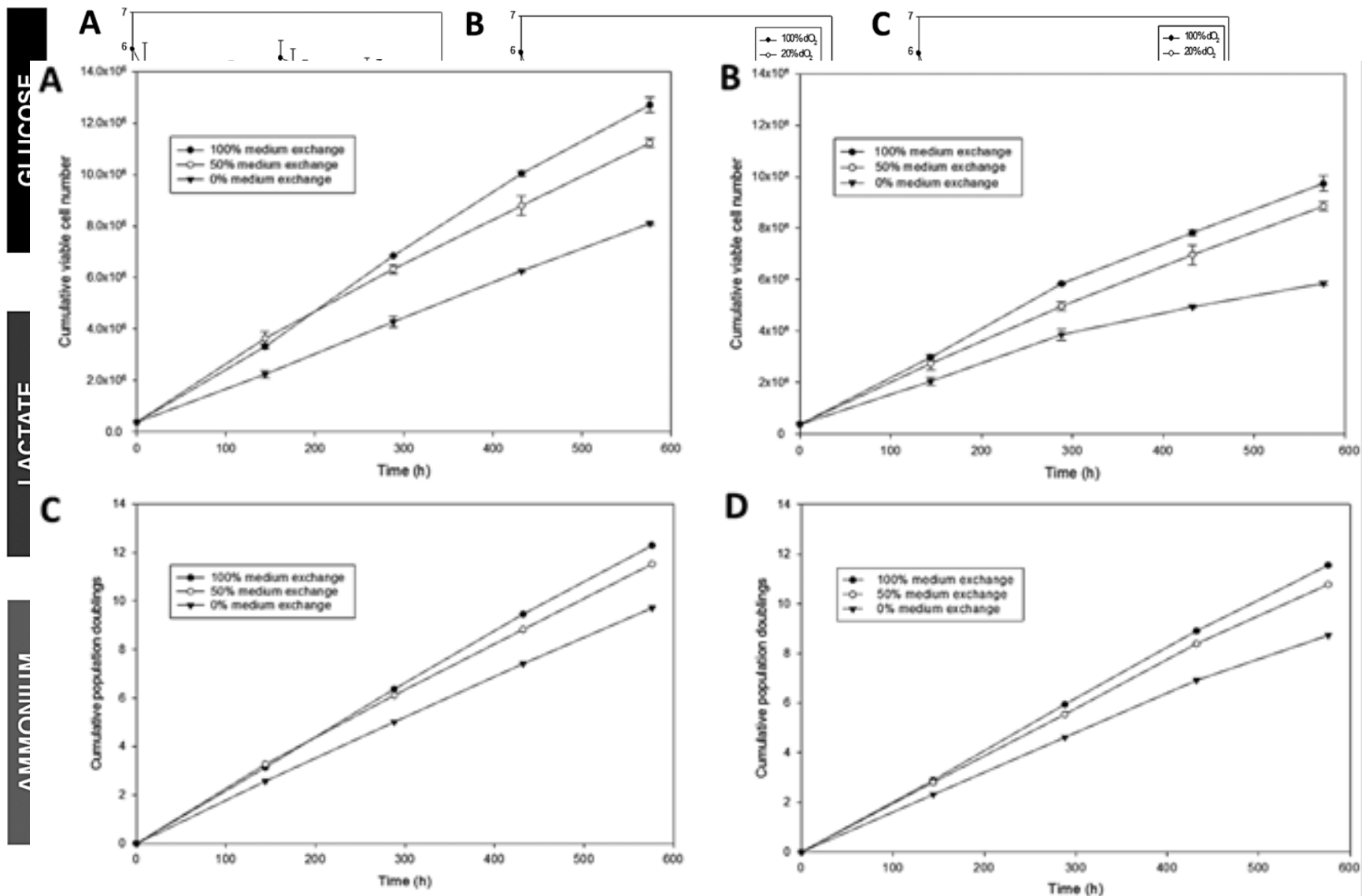

D

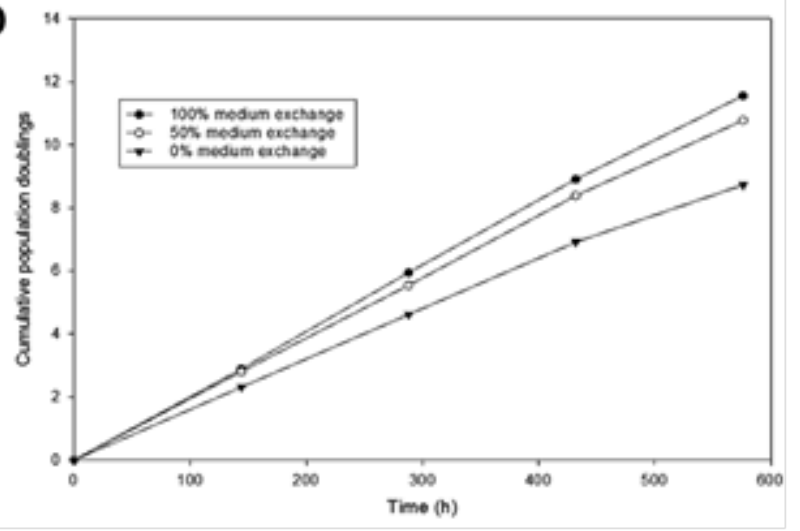

Figure 1. Cumulative cell number for (A) $100 \% \mathrm{dO}_{2}$ at saturation $\left(20 \% \mathrm{O}_{2} \mathrm{v} / \mathrm{v}\right.$ gas phase) and (B) $20 \%$ $\mathrm{dO}_{2}$ at saturation (4\% $\mathrm{O}_{2} \mathrm{v} / \mathrm{v}$ gas phase) for $100 \%, 50 \%$ and $0 \%$ medium exchange conditions. Cumulative population doublings for (C) $100 \% \mathrm{dO}_{2}$ at saturation (20\% $\mathrm{O}_{2} \mathrm{v} / \mathrm{v}$ gas phase) and (D) $20 \%$ $\mathrm{dO}_{2}$ at saturation (4\% $\mathrm{O}_{2} \mathrm{v} / \mathrm{v}$ gas phase) for $100 \%, 50 \%$ and $0 \%$ medium exchange conditions (Mean value $\pm \mathrm{SD}, \mathrm{n}=4)$.

Figure 2. The effect of medium exchange and dissolved oxygen concentration over four serial passages on metabolite consumption and production. Daily medium samples were collected from each experimental condition and glucose, lactate and ammonium concentrations measured. Change in glucose concentration for $100 \%$ and $20 \% \mathrm{dO}_{2}$ for $100 \%$ (A), $50 \%$ (B) and $0 \%$ (C) medium exchange conditions. Change in lactate concentration for $100 \%$ and $20 \% \mathrm{dO}_{2}$ for $100 \%$ (D), 50\% (E) and $0 \%(\mathrm{~F})$ medium exchange conditions. Change in ammonium concentration for $100 \%$ and $20 \% \mathrm{dO}_{2}$ for $100 \%(\mathrm{G}), 50 \%$ (H) and $0 \%(\mathrm{I})$ medium exchange conditions. (Mean value $\pm \mathrm{SD}, \mathrm{n}=4$ ). 

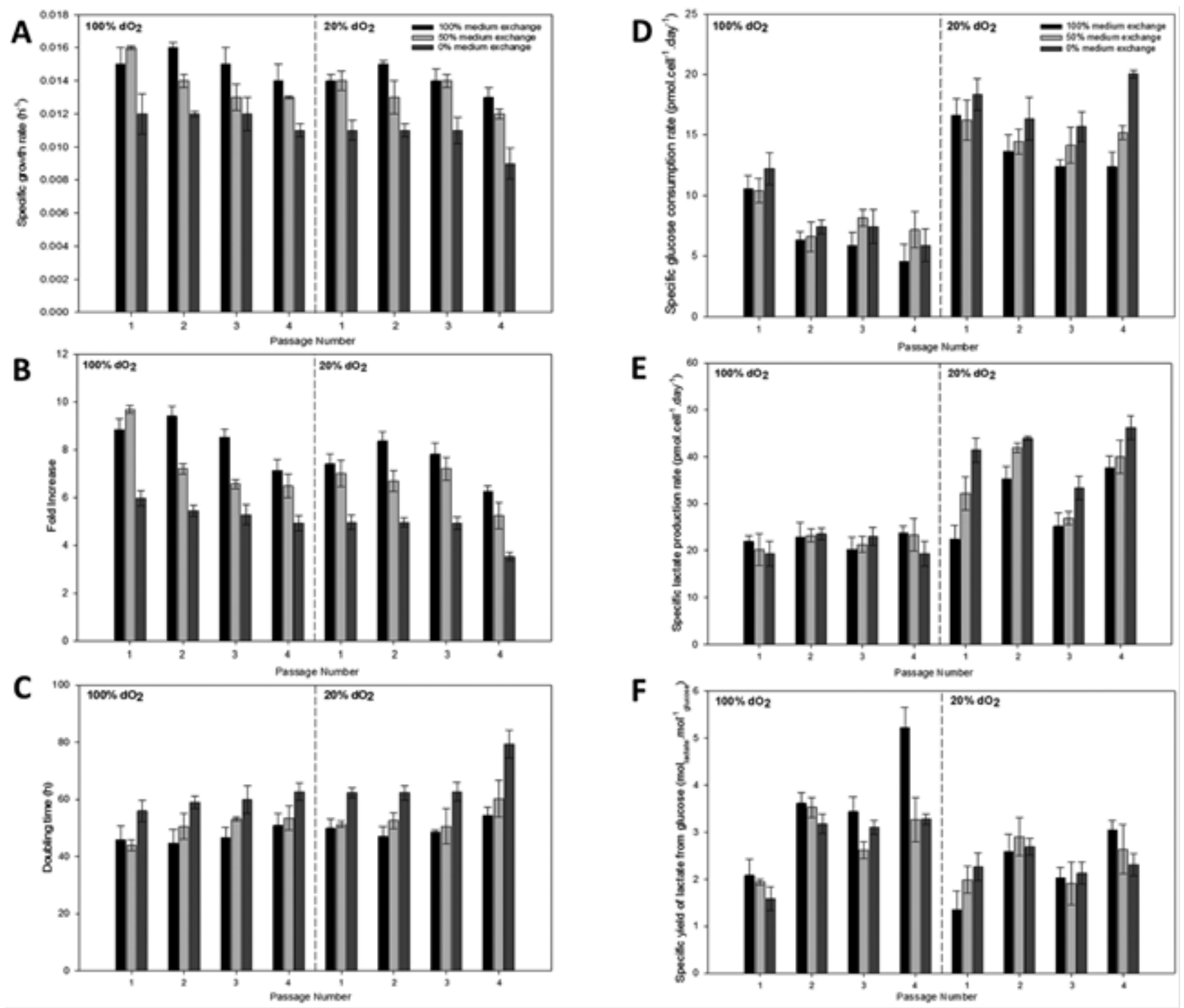

Figure 3. Impact of $\mathrm{dO} 2$ concentration $\left(100 \% \mathrm{dO}_{2}\right.$ and $\left.20 \% \mathrm{dO}_{2}\right)$ and medium exchange $(100 \%, 50 \%$ and 0\%) over four serial passages on (A) Specific growth rate; (B) Fold increase; (C) Doubling time; (D) Specific glucose consumption rate; (E) Specific lactate production rate; (F) Yield of lactate from glucose. $100 \% \mathrm{dO}_{2}$ values are on the left hand side of the plot and $20 \% \mathrm{dO}_{2}$ values are on the right hand side of the plot. $100 \%$ medium exchange conditions are represented by the black bars, $50 \%$ medium exchange conditions are represented by the grey bars and $0 \%$ medium exchange conditions are represented by the clear bars. (Data show mean $\pm S D, n=4$ ). 

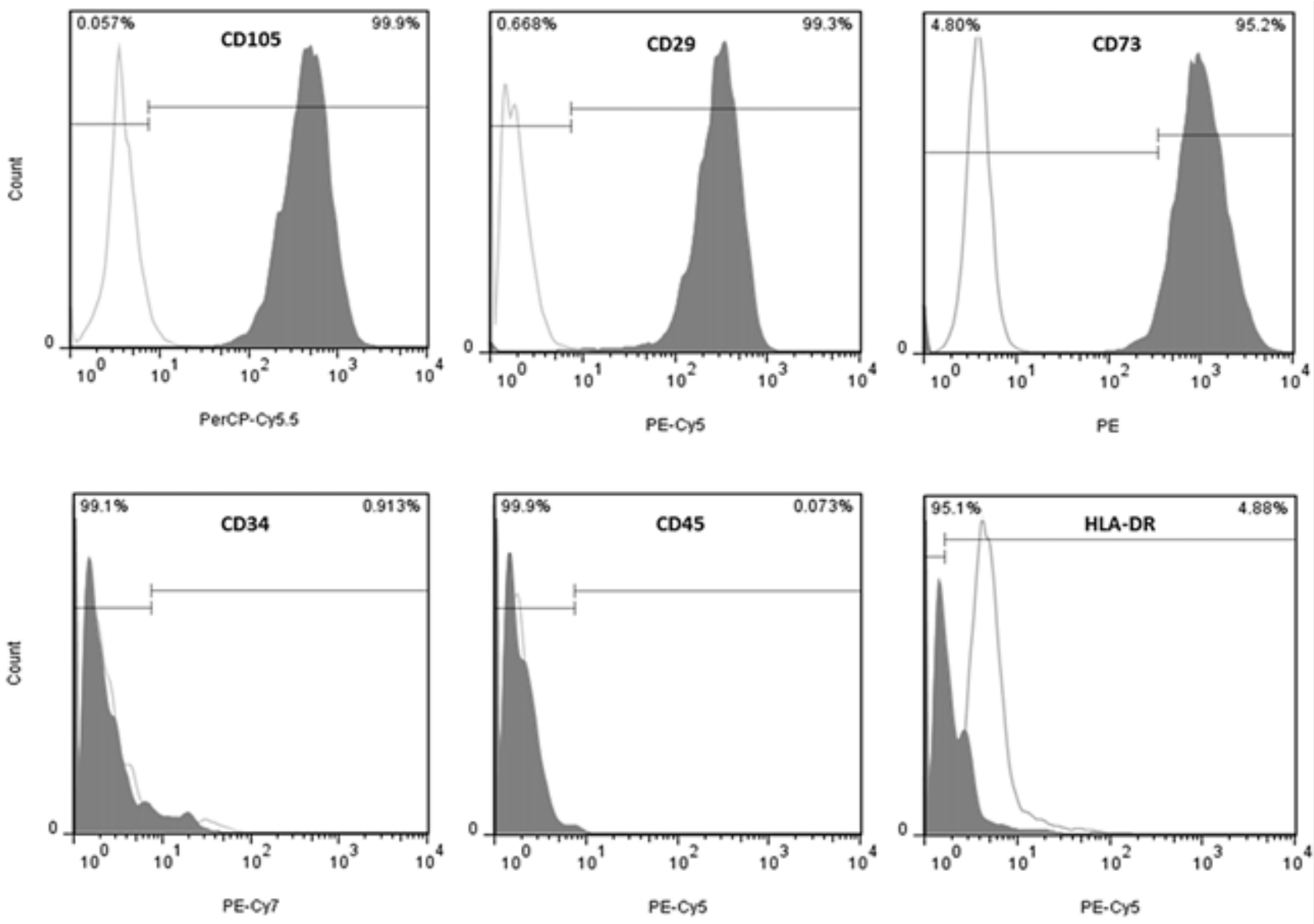

Figure 4. Immunophenotype analysis of hMSCs before inoculation and after passage 4. (A) Flow cytometry data displayed are from the $50 \%$ medium exchange condition cultured at $20 \% \mathrm{dO}_{2}$ at saturation. Similar results were obtained for all experimental conditions. Open profiles represent the isotype control, filled profiles represent expression of the antibody conjugated cell surface marker. Gates are set at $95 \%$ of the isotype control. 

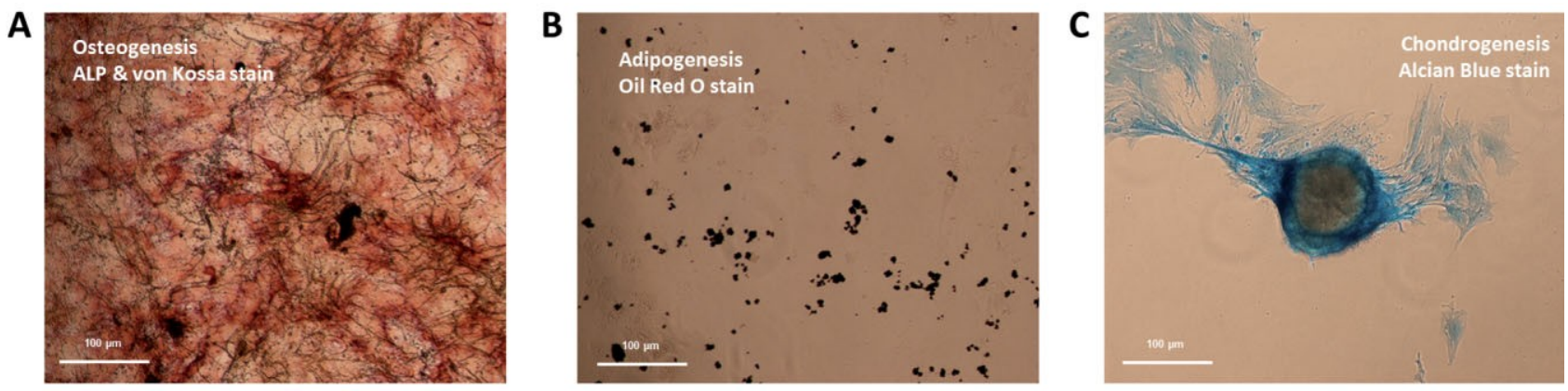

Figure 5. Histology demonstrating hMSC multipotency after passage 4. Images displayed are from the $50 \%$ medium exchange condition cultured at $20 \% \mathrm{dO}_{2}$ at saturation. Similar results were obtained for all experimental conditions. Magnification 10×. (A) Phase-contrast image demonstrating osteogenic differentiation of hMSCs after induction with a differentiation-specific medium and staining with Alkaline Phosphatase and Von Kossa stains. (B) Phase-contrast image demonstrating adipogenic differentiation of hMSCs after induction with a differentiation-specific medium and staining with Oil Red O. (C) Phase-contrast image demonstrating chondrogenic differentiation of hMSCs after induction with a differentiation-specific medium and staining with Alcian Blue. 